\title{
SUSTITUCIÓN DE EMPLEADOR ${ }^{1}$
}

\author{
EMPLOYMENT SUBSTITUTION
}

César Alfredo Puntriano Rosas

Universidad ESAN, Perú

https: / / orcid.org/0000-0002-4814-0112

\section{Resumen}

La compra y venta de empresas, fusiones, escisiones, reorganizaciones en general constituyen operaciones sumamente complejas y que impactan, como es natural, en las relaciones societarias subyacentes a las compañías que son objeto de ellas. También se produce un efecto natural en la tributación de las corporaciones y las personas involucradas. Sin embargo, una arista fundamental es el efecto que dichas operaciones causan en las relaciones de trabajo del personal de las empresas participantes. En el presente artículo se analizan el mencionado efecto y las respuestas dadas por el ordenamiento jurídico peruano.

Palabras clave: empleador, reorganización societaria, sustitución, continuidad, cesión.

\section{Abstract}

The purchase of companies, mergers, spin-offs, reorganizations in general, constitute extremely complex operations that impact, of course, the underlying corporate relationships to the companies that are subject to them. There

1 Una versión anterior de este artículo fue publicada en Normas Legales: Análisis Jurídico (n. ${ }^{\circ}$ 356, de enero del 2006, págs. 139-162), revista de la Editorial Normas Legales, con el título «Notas sobre la reorganización societaria y el principio de continuidad de la relación laboral». 
is also a natural effect on the taxation of corporations and people involved. However, a fundamental edge is the effect of said operations on the working relationships of personnel employed by the participating companies. In this article we analyze the aforementioned effect and the existence of responses by our legal system.

Keywords: Employer, corporate reorganization, substitution, continuity, assignment.

\section{Introducción}

Según el informe trimestral de TTR (Transactional Track Record)², el mercado de fusiones y adquisiciones en el Perú ha cerrado el segundo trimestre del año 2019 con 65 transacciones y con más de dos mil millones de dólares en capital movilizado. Esto demuestra que, pese a la ralentización de nuestra economía -pues el PBI creció menos del 3\% en lo que va del año-, la reorganización empresarial se mantiene como una opción para maximizar la productividad, reducir costos, crear economías de escala e, inclusive, dominar un sector del mercado. Un ejemplo palpable de esto último ocurrió, por ejemplo, con la adquisición de 21st Century Fox por parte de The Walt Disney Company por una suma cercana a los 70,000 millones de dólares.

Estas decisiones empresariales tienen, desde luego, consecuencias para los trabajadores involucrados, como ceses colectivos, renuncias, despidos, pues en algunos casos se presenta un fenómeno de excedencia de personal y, en otros, sin llegar a la reducción de la planilla, se requiere uniformizar condiciones de trabajo.

En las líneas que siguen se formularán algunas reflexiones sobre tales cambios en la organización empresarial y su impacto en las relaciones laborales.

2 El reporte completo puede ubicarse en: Transactional Track Record, Peru: Quaterly report (2019): disponible en https://www.ttrecord.com/es/publicaciones/informe-por-mercado/ informe-mensual-peru/Peru-2T-2019/1886/ 


\section{Principales mecanismos legales de reorganización empresarial}

Son tres los principales mecanismos legales de reorganización empresarial: la fusión, la escisión y la reorganización simple.

\subsection{Fusión de sociedades}

Como lo afirma Julio C. Otaegui, citado por Elías Laroza:

... la fusión como institución propia del derecho de las personas jurídicas se caracteriza por implicar la unificación de dos o más personas jurídicas en una sola [...] en el campo del derecho de las sociedades la fusión es una de las vías por las que se instrumenta la concentración de empresas, obteniéndose la unión económica y jurídica de las respectivas sociedades, mientras que por los otros métodos de concentración antes expuestos se logra la unión económica pero se mantienen las diversas personalidades jurídicas de las sociedades interesadas [...] Mediante la fusión, los patrimonios de dos o más sociedades que denominaremos sociedades fusionantes se unifican en un solo patrimonio $y$, consecuentemente, en vez de coexistir varias personas jurídicas o sujetos de derecho existirá en lo sucesivo una sola persona jurídica o sujeto de derecho que llamaremos sociedad fusionaria... ${ }^{3}$.

A partir de lo establecido en el artículo 344 de la Ley 26887, Ley General de Sociedades (en adelante, LGS), es posible indicar que se está ante una fusión de sociedades cuando, dos o más de ellas, en virtud de un convenio suscrito, transfieren en bloque, y en un solo acto, el íntegro de su patrimonio a una nueva sociedad o a una de ellas, con la consiguiente extinción de las transferentes y, en su caso, la entrega o atribución en contraprestación de partes sociales de la sociedad adquirente a los socios de las que se extinguen*.

\subsubsection{Formas de fusión}

De acuerdo con lo establecido por el artículo 344 de la LGS, la fusión puede revestir cualquiera de las siguientes formas: por incorporación y por absorción.

3 Julio Otaegui, Fusión y escisión de sociedades comerciales. Citado por Enrique Elías Laroza, Derecho societario peruano (Trujillo: Editorial Normas Legales, 2000), 915.

4 Manual Societario, tomo 2 (Lima: Editorial Economía y Finanzas, s. f.), 502. 
En el caso de la fusión por incorporación, el resultado es la creación de una nueva sociedad. La sociedad transferente del bloque patrimonial se denomina incorporada, y la adquirente, incorporante (inciso 1).

Como lo afirma Elías Laroza ${ }^{5}$, esta forma de fusión consiste en:

a) La reunión de los patrimonios integrales de dos o más sociedades, con el objeto de formar uno solo.

b) La transmisión del patrimonio para constituir o incorporar una nueva sociedad, que lo recibe.

c) La extinción de la personalidad jurídica de todas las sociedades que son incorporadas.

d) El traspaso en bloque y a título universal de los patrimonios de las sociedades que se extinguen, pues cada uno es un conjunto integral y único de activos y pasivos.

e) La recepción de acciones o participaciones de la nueva sociedad incorporante por parte de los socios o accionistas de las sociedades que se extinguen a causa de la fusión, a cambio de las que tenían en estas, salvo casos de excepción.

En la fusión por absorción, una sociedad ya existente absorbe a una o más sociedades. La transferente recibe el nombre de absorbida, y la adquirente, de absorbente.

Elías Laroza ${ }^{6}$ afirma que esta fusión se caracteriza por:

a) La absorción por parte de una sociedad (absorbente) de los patrimonios integrales de otra $\mathrm{u}$ otras sociedades (absorbidas) con el fin de formar uno solo.

b) La extinción de la personalidad jurídica de la sociedad o sociedades que son absorbidas.

c) El traspaso en bloque y a título universal de los patrimonios de la sociedad o sociedades absorbidas, pues cada uno es un conjunto integral y único de activos y pasivos.

d) Los socios o accionistas de las sociedades absorbidas reciben, a cambio de las que tenían en estas, acciones o participaciones de la sociedad absorbente, salvo casos de excepción.

5 Elías Laroza, Derecho societario, 920.

6 Elías Laroza, Derecho societario, 921. 
e) La recepción de acciones o participaciones de la sociedad absorbente por parte de los socios o accionistas de las sociedades absorbidas, a cambio de las que tenían en estas, salvo casos de excepción.

Es importante precisar que «esa doble modalidad de fusión no hace variar la esencia íntima del fenómeno jurídico, pues en ambos supuestos se produce la unificación de patrimonios, de socios y de relaciones jurídicas que es característica de la fusión. La diferencia entre ambos procesos de fusión es puramente externa y formal, no sustancial...» .

\subsubsection{Características de la fusión}

Las principales características de la fusión son las siguientes:

a) La transferencia de todo el patrimonio en bloque y a título universal (in universum ius) de las sociedades absorbidas a la sociedad absorbente o de las sociedades a fusionarse a la nueva sociedad.

b) La extinción de la personalidad jurídica de las sociedades absorbidas o incorporadas.

c) La atribución inmediata a los accionistas de las sociedades absorbidas o de las sociedades fusionantes de acciones de la sociedad absorbente o de la sociedad nueva.

La LGS señala que la sociedad fusionada se extingue sin liquidarse, existiendo una sucesión a título universal del patrimonio de la sociedad fusionada con la fusionante, en bloque y en un solo acto (artículo 344 de la LGS). En ese sentido, la fusionante asumirá el conjunto de derechos y deberes transmisibles de los que era titular la fusionada en el momento de la fusión. Asimismo, los socios de la sociedad extinguida pasan a serlo de la absorbente o incorporante. Esto se produce mediante la entrega de acciones o atribución de participaciones, según sea el caso, por la absorbente o incorporante a favor de aquellos.

Conforme lo señala el artículo 345 de la LGS, la fusión «se acuerda con los requisitos establecidos por la ley y el estatuto de las sociedades participantes para la modificación de su pacto social y estatuto».

7 Joaquín Garrigues y Rodrigo Uría, Comentario a la Ley de Sociedades Anónimas. Citado por Elías Laroza, Derecho societario, 921.

8 Elías Laroza, Derecho societario, 922. 
La Junta General o Asamblea de cada una de las sociedades participantes aprueba el proyecto de fusión con las modificaciones que acuerden y fija una fecha común para la entrada en vigencia de la fusión (artículo 351, primer párrafo, de la LGS).

El primer párrafo del artículo 353 de la LGS establece que «la fusión entra en vigencia en la fecha fijada en los acuerdos de fusión. En esa fecha cesan las operaciones y los derechos y obligaciones de las sociedades que se extinguen, los que son asumidos por la sociedad absorbente e incorporante...».

Siguiendo a Elías Laroza`, «la solución es simple: las juntas o asambleas fijan una fecha de entrada en vigencia, ratificando o variando la sugerida en el proyecto de fusión...».

En ese sentido, y para efectos laborales, la vigencia de la fusión se contará desde el acuerdo que las sociedades intervinientes tomen sobre ella.

\subsection{Escisión de sociedades}

El primer párrafo del artículo 367 de la LGS señala que «por la escisión una sociedad fracciona su patrimonio en dos o más bloques para transferirlos íntegramente a otras sociedades o para conservar uno de ellos, cumpliendo los requisitos y las formalidades prescritas por esta ley».

La doctrina autorizada afirma al respecto que:

... si bien la mecánica de la escisión es inversa a la de la fusión, no se puede concluir de ello que los efectos económicos de ambas operaciones sean también inversos. La fusión, por su parte, implica siempre una concentración de empresas [...] pero la escisión es un acto societario mucho más complejo. En efecto, la desmembración del patrimonio de las sociedades escindentes es solamente un aspecto de la operación. Pero a ello sigue, a diferencia de la fusión, que termina en el acto mismo de la consolidación de los patrimonios, un destino, diferente, en la escisión, para los distintos bloques patrimoniales que se apartan de la sociedad escindente, desde que pueden ser asignados a personas jurídicas recién constituidas o a otras preexistentes. Por otra parte, hay otro elemento en juego que hace aún más compleja la escisión: en la fusión la consolidación de patrimonios

9 Elías Laroza, Derecho societario, 952. 
se realiza siempre en una sola sociedad, sea absorbente o incorporante, según el caso, mientras que en la escisión la sociedad escindente puede extinguirse o subsistir; $y$, en este último caso, también la escindente puede recibir bloques patrimoniales de otra $u$ otras sociedades, cuando la escisión tiene carácter múltiple. Esta variedad de factores determina que en la escisión no siempre el efecto económico es el mismo...» ${ }^{10}$.

\subsubsection{Formas de escisión}

La LGS ha optado por dos formas únicas de escisión, descritas en los artículos 367 y 368: la escisión propia o total y la escisión impropia o parcial.

\section{Escisión propia o total}

Prevista en el inciso 1 del artículo 367 de la LGS, implica la extinción de la personalidad jurídica de la sociedad escindente; por esta razón se denomina total. Algunos la llaman propia porque, al crearse la figura de la escisión, se entendía como tal solamente a aquella que requería la extinción de la persona jurídica escindente.

Así, el citado artículo señala que una de las formas de la escisión consiste en «La división de la totalidad del patrimonio de una sociedad en dos o más bloques patrimoniales, que son transferidos a nuevas sociedades o absorbidos por sociedades ya existentes o ambas cosas a la vez. Esta forma de escisión produce la extinción de la sociedad escindida...».

Siguiendo a Elías Laroza ${ }^{11}$, las características de esta forma de escisión son, entre otras, las siguientes:

a) La totalidad del patrimonio de la sociedad escindente se fracciona o divide en dos bloques patrimoniales o más, los que se transfieren a sociedades beneficiarias de la acción.

b) La personalidad jurídica de la sociedad escindente se extingue como resultado de la escisión.

c) Aquellas sociedades que reciben bloques patrimoniales pueden ser sociedades nuevas, existentes o ambas.

10 Elías Laroza, Derecho societario, 790.

11 Elías Laroza, Derecho societario, 985. 
d) En caso de que la sociedad que recibe el bloque patrimonial sea nueva, su capital social tendrá un monto equivalente al valor neto adjudicado al bloque patrimonial que recibe y emitirá acciones o participaciones por ese importe, para lo cual se aplicará la relación de canje acordada.

e) Si la sociedad que recibe el bloque patrimonial es preexistente, incrementará su capital social por una cifra igual al valor neto adjudicado al bloque patrimonial que recibe y emitirá acciones o participaciones por ese importe; en este caso se aplicará la relación de canje acordada.

f) Las acciones o participaciones que emite la sociedad que se crea, o bien la preexistente, se entregan a los socios de la sociedad escindente en similar proporción a la que estos tenían en el capital de esta última, salvo pacto en contrario que establezca otras proporciones de cada sociedad beneficiaria.

\section{Escisión impropia o parcial}

Esta forma de escisión se encuentra regulada en el inciso 2 del artículo 367 de la LGS. Es parcial porque la sociedad escindente no se extingue y mantiene en su poder una de las porciones patrimoniales en que se fracciona.

De acuerdo con Elías Laroza ${ }^{12}$, se la ha denominado impropia, puesto que se trata de una figura de escisión que no cumplía con una característica considerada esencial: la extinción de la sociedad escindente.

El referido inciso 2 afirma que esta forma de escisión consiste en «La segregación de uno o más bloques patrimoniales de una sociedad que no se extingue y que los transfiere a una o más sociedades nuevas, o son absorbidos por sociedades existentes o ambas cosas a la vez. La sociedad escindida ajusta su capital en el monto correspondiente».

Los elementos característicos de esta forma de escisión son los siguientes ${ }^{13}$ :

a) El patrimonio total de la sociedad escindente se fracciona en dos o más bloques patrimoniales, uno de los cuales queda en poder de la escindente, la que, entonces, no se extingue.

b) El segundo o demás bloques patrimoniales comprendidos en la escisión se transfieren a otra $\mathrm{u}$ otras sociedades beneficiarias de la escisión, con el consiguiente ajuste de capital de la sociedad escindente.

12 Elías Laroza, Dere cho societario, 986.

13 Elías Laroza, Derecho societario, 986. 
c) Las sociedades que reciben los bloques patrimoniales pueden ser nuevas, preexistentes o ambas a la vez.

d) En caso de que la sociedad que recibe el bloque patrimonial sea nueva, su capital social tendrá un monto equivalente al valor neto adjudicado al bloque patrimonial que recibe y emitirá acciones o participaciones por ese importe, aplicándose la relación de canje acordada.

e) Si la sociedad que recibe el bloque patrimonial es preexistente, incrementará su capital social por una cifra igual al valor neto adjudicado al bloque patrimonial que recibe y emitirá acciones o participaciones por ese importe, aplicándose la relación de canje acordada.

f) Las acciones o participaciones que emite la sociedad que se crea o la preexistente se entregan a los socios de la sociedad escindente en similar proporción a la que estos tenían en el capital de esta última, salvo pacto en contrario que establezca otras proporciones para cada sociedad beneficiaria.

\subsubsection{Características de la escisión}

Elías Laroza afirma que no existe unanimidad doctrinaria en cuanto a los caracteres esenciales de la escisión, que, en su opinión, son los siguientes ${ }^{14}$ :

a) La transmisión de patrimonios en bloque, de las sociedades escindentes a las beneficiarias, bajo la forma de «bloques patrimoniales».

b) La extinción de la personalidad jurídica de la sociedad escindente, en la escisión total o propia, sin que ello implique ni disolución ni liquidación.

c) La subsistencia de la persona jurídica escindente, en la escisión parcial o impropia, con el consiguiente ajuste de su capital, salvo excepciones.

d) La formación del capital social de las sociedades beneficiarias de la escisión, cuando se trata de sociedades nuevas. Y el aumento de capital de las sociedades beneficiarias preexistentes, con excepciones.

e) La entrega de las acciones o participaciones que sean emitidas por las sociedades beneficiarias, en favor de los socios de la sociedad escindente.

14 Elías Laroza, Derecho societario, 992. 


\subsubsection{Aprobación de la escisión}

El artículo 371 de la LGS establece que el directorio de cada una de las sociedades que participan en la escisión aprueba, con el voto favorable de la mayoría absoluta de sus miembros, el texto del proyecto de escisión. En el caso de sociedades que no cuenten con un directorio, el proyecto de escisión se aprueba por la mayoría absoluta de las personas encargadas de la administración de la sociedad.

Por otra parte, el artículo 378 de la LGS señala que la escisión entra en vigencia en la fecha fijada en el acuerdo en que se aprueba el proyecto para efectuarla. A partir de ese día las sociedades beneficiarias asumen automáticamente las operaciones, derechos y obligaciones de los bloques patrimoniales escindidos y cesan con respecto a ellos las operaciones, derechos y obligaciones de la o las sociedades escindidas, ya sea que se extingan o no.

\subsection{Reorganización simple de sociedades}

Como lo establece el artículo 391 de la LGS, la reorganización es el acto por el cual una sociedad segrega uno o más bloques patrimoniales y los aporta a una o más sociedades nuevas o existentes, recibiendo a cambio y conservando en su activo las acciones o participaciones correspondientes a dichos aportes.

Las características de la reorganización simple son las siguientes ${ }^{15}$ :

a) Los bloques patrimoniales segregados pueden ser uno o más, en la misma operación.

b) La LGS califica expresamente de «aportes» a las transferencias de los bloques patrimoniales a las sociedades que los reciben, sean nuevas o preexistentes.

c) La LGS señala que las acciones o participaciones que emiten a cambio las sociedades receptoras corresponden a la aportante, la cual las recibe y conserva en su activo. Con esta fórmula, la norma desea simplemente destacar que la sociedad aportante recibe las acciones o participaciones no para entregarlas a sus socios sino para conservarlas. En otras palabras, enfatiza que, como resultado de esta forma de reorganización, la sociedad recibe las acciones para sí y no para sus socios, pues esa es la diferencia

15 Elías Laroza, Derecho societario, 992. 
sustancial con el mecanismo de la escisión parcial. No existe impedimento de su libre transferencia en cualquier clase de operación posterior.

En conclusión, «el artículo 391 de la LGS permite que estos aportes de bloques patrimoniales puedan ser clasificados como una forma de reorganización societaria, pues es la que normalmente se emplea para desconcentrar una sociedad en un grupo de sociedades, mediante conversión de la persona jurídica original en una sociedad holding. Pero, aun siendo un claro ejemplo de reorganización y desconcentración empresarial, no cumple con los caracteres esenciales de una escisión ${ }^{16}$.

\section{El principio de continuidad y su vinculación con la reorganización societaria}

Habiendo realizado un breve desarrollo conceptual sobre las modalidades más conocidas (y empleadas) de reorganización societaria, en este numeral el enfoque se centrará en las repercusiones en las relaciones de trabajo del personal de las empresas que optan por reorganizarse. Para el efecto, el derecho laboral ha concebido el principio de continuidad, como parámetro que presupone un contrato de trabajo de tracto sucesivo que permanece en el tiempo, sin dejar de lado, desde luego, el entorno social y económico.

\subsection{Aproximación teórica y alcances del principio de continuidad de relación laboral}

El profesor Américo Plá afirma que: «Para comprender este principio debemos partir de la base de que el contrato de trabajo es un contrato de tracto sucesivo, o sea, que la relación laboral no se agota mediante la realización instantánea de cierto acto, sino que dura en el tiempo. La relación laboral no es efímera, sino que presupone una vinculación que se prolonga» ${ }^{17}$.

Así, la naturaleza de este principio fundamental del derecho del trabajo considera al contrato de trabajo como uno de duración indeterminada, resistente a las vicisitudes que pudieran devenir en el desarrollo de la relación

16 Elías Laroza, Derecho societario, 1044.

17 Américo Plá Rodríguez, Los principios del derecho del trabajo, 3. ${ }^{a}$ ed. (Buenos Aires: Editorial Desalma, 1998), 215. 
laboral. En palabras de De los Heros, «se trata de otorgar la mayor seguridad, dentro de la racionalidad de la relación jurídica laboral, al trabajo humano, entendiendo que tal seguridad redundará en beneficio no solo del trabajador y su desarrollo personal y familiar, sino también en beneficio del empleador para quien trabaja, todo lo cual tiene una proyección indudable en términos económicos y de promoción social...» ${ }^{18}$.

Para resumir el significado de este principio, es interesante una cita del profesor Alonso Olea, que el propio Plá toma como ejemplificadora de aquel: «El contrato de trabajo es, por así decirlo, un negocio jurídico de extremada vitalidad, de una gran dureza y resistencia en su duración $»^{19}$.

En cuanto a la existencia de este principio, se debe indicar que fue pensado a favor del trabajador, lo cual no significa que este se encuentre atado al contrato de trabajo en virtud de aquel. Recuérdese que, en ejercicio de su libertad de trabajo, el trabajador puede optar por resolver su vínculo laboral ${ }^{20}$.

Sin embargo, resulta innegable que la mayor prolongación de la permanencia del trabajador en la empresa es también beneficiosa para él, y esto en razón no solamente de su estado anímico, sino también por su experiencia y conocimiento adquiridos a lo largo de los años. Como se sabe, en el disputado mercado laboral peruano, la ventaja competitiva empresarial radica muchas veces en la calificación de su mano de obra.

En consecuencia, la idea que fundamenta este principio consiste en que, si una empresa ha sido creada para realizar sus actividades y cumplir sus objetivos en un plazo indeterminado, resulta en principio lógico - y por ende razonable- que los trabajadores, que tienen a su cargo cumplir ese objetivo, permanezcan en sus puestos de trabajo tanto tiempo como sea posible y naturalmente por decisión del trabajador, que es libre de renunciar, porque dicho principio ha sido concebido a su favor ${ }^{21}$.

18 Alfonso de los Heros Pérez Albela, «Los contratos de trabajo de duración determinada: ¿regla o excepción?», en Los principios del derecho del trabajo en el derecho peruano. Libro homenaje al profesor Américo Plá Rodríguez (Lima: Grijley, 2004), 196.

19 Manuel Alonso Olea, Derecho del trabajo. Citado por Plá Rodríguez, Los principios del derecho del trabajo, 215.

20 El ordenamiento laboral peruano exige que la renuncia se presente al empleador por escrito, con una anticipación de treinta días (30) calendario, pudiendo el trabajador solicitar que se le exonere de dicho plazo.

21 Pedro Morales Corrales, «Sucesión empresarial», en Los principios del derecho del trabajo, 258259. 
En cuanto a los alcances del principio de continuidad, según lo indica Plá ${ }^{22}$, pueden atribuírsele las siguientes proyecciones:

a) Preferencia por los contratos de duración indefinida.

b) Amplitud para la admisión de las transformaciones del contrato.

c) Facilidad para mantener el contrato a pesar de los incumplimientos o nulidades en que se haya incurrido.

d) Resistencia a admitir la rescisión unilateral del contrato, por voluntad de la parte patronal.

e) Interpretación de las interrupciones de los contratos como simples suspensiones.

f) Prolongación del contrato en casos de sustitución del empleador.

Podemos decir que la continuidad se impone sobre el fraude, la variación, la infracción, la arbitrariedad, la interrupción y la sustitución.

\subsection{El principio de continuidad y la sustitución del empleador}

Con respecto a la sustitución del empleador, Plá señala que «otra de las características que presenta el contrato de trabajo en la realidad, es que sufre no solo novaciones objetivas, sino también subjetivas. O sea, que no solo cambian las condiciones de trabajo, sino los protagonistas del contrato» ${ }^{23}$.

Desde luego, la novación subjetiva corresponde a la posición del empleador pues, al ser el contrato de trabajo intuito personae (personalísimo), la prestación de la parte laboral es insustituible.

A guisa de ejemplo, la doctrina española — citando el artículo 44 del Estatuto de los Trabajadores de España ${ }^{24}$ - afirma que ${ }^{25}$ el cambio del empresario

22 Plá Rodríguez, Los principios del derecho del trabajo, 223.

23 Plá Rodríguez, Los principios del derecho del trabajo, 267.

24 Norma que regula expresamente la sucesión empresarial señalando que:

Artículo 44. La sucesión de empresa.

1. El cambio de la titularidad de la empresa, centro de trabajo o de una unidad productiva autónoma de la misma, no extinguirá por sí mismo la relación laboral, quedando el nuevo empresario subrogado en los derechos y obligaciones laborales del anterior. Cuando el cambio tenga lugar por actos inter vivos, el cedente, y, en su defecto, el cesionario, está obligado a notificar dicho cambio a los representantes legales de los trabajadores de la empresa cedida, respondiendo ambos solidariamente durante tres años de las obligaciones laborales nacidas con anterioridad a la transmisión y que no hubieran sido satisfechas.

2. El cedente y el cesionario responderán también solidariamente de las obligaciones nacidas con posterioridad a la transmisión, cuando la cesión fuese declarada delito.

25 Manuel Alonso Olea y María Emilia Casas Baamonde, Derecho del trabajo (Madrid: Civitas, 2001), 393. 
no produce la extinción de los contratos de trabajo ni los modifica, salvo la novación subjetiva. Esto se justifica en lo siguiente:

a) En primer lugar, la prestación fundamental del empleador, la salarial, no es personalísima, ya que consiste en dar un bien, por lo general inespecífi$\mathrm{co}$, a diferencia de la perspectiva del trabajador, cuya prestación básica (la de trabajar) requiere emplear a su persona.

b) En segundo lugar, aunque el contrato de trabajo envuelve prestaciones personalizadas del empresario (dar trabajo, proteger a su empleado), a pesar de ellas, la resistencia del contrato se impone, y de ahí resulta su continuidad y conservación, pese a los cambios de empleador.

En consecuencia, en aplicación del principio de continuidad, en cuanto a la sustitución del empleador, la relación laboral, de tracto sucesivo, continuará en el tiempo, en las mismas condiciones en las que se encontraba antes.

Respecto de la delimitación del supuesto de sustitución empresarial, coincidimos con el profesor Alonso Olea ${ }^{26}$, en el sentido de que el fenómeno de la continuidad de las relaciones laborales frente a una sustitución del empleador opera respecto de la integridad de la empresa o de un centro de trabajo, identificados tanto localmente como en su acepción de organización. La expresión centro de trabajo debe ser entendida con gran amplitud, abarcando «servicios y actividades parciales», «centro de explotación», «unidad de negocios», etc. Lo que se quiere, indica con acierto Olea ${ }^{27}$, es comprender a la transferencia o cambio de titularidad no solo de la empresa sino también del centro de explotación empresarial, sea este una unidad parcial o autónoma dentro de aquella (visión amplia sobre centro de trabajo).

Como lo afirman Martín Valverde, Rodríguez-Sañudo y García Murcia ${ }^{28}$, a propósito del artículo 44.1 del Estatuto de los Trabajadores de España ${ }^{29}$, el supuesto de la continuidad de la relación laboral frente a una sustitución del empleador comprende la venta de empresa, la adquisición en subasta pública de una empresa en funcionamiento, así como los casos en los que no se produce cambio en la titularidad patrimonial sino en la titularidad de la explotación, como el arrendamiento de industria, el arrendamiento de negocio y su posterior reversión al arrendador, finalización de la concesión administrativa

26 Alonso Olea y Casas Baamonde, Derecho del trabajo, 394.

27 Alonso Olea y Casas Baamonde, Derecho del trabajo, 395.

28 Antonio Martín Valverde, Fermín Rodríguez-Sañudo Gutiérrez y Joaquín García Murcia, Derecho del trabajo, 5. ${ }^{\text {a }}$ ed. (Madrid: Tecnos, 1996), 659.

29 Ver nota 43 
con continuidad de la actividad por el ente público que la realizó, fusiones y absorciones de sociedades, entre otras.

Asimismo, en lo que se refiere al objeto de la transmisión, este no es necesariamente la totalidad de la empresa como unidad, ya que puede tratarse de una transmisión parcial. Es importante, de acuerdo con Martín Valverde, Rodríguez-Sañudo y García Murcia ${ }^{30}$, que lo que se transmita sea susceptible de una explotación económica independiente capaz de ofrecer bienes y servicios al mercado ${ }^{31}$. No lo es, por ejemplo, la enajenación por separado de diversos elementos de la empresa a distintas personas ${ }^{32}$, la venta de una parte de los bienes de la empresa, pero sin organización empresarial propiamente dicha ${ }^{33}$, o el desahucio de un simple local del negocio ${ }^{34}$.

Así, y en cuanto a las modalidades de reorganización empresarial que se comenta en el presente trabajo, operará el principio de continuidad en la fusión de sociedades, en la fusión tanto por absorción como por incorporación, en la escisión propia e impropia, y en la reorganización simple. En este último caso deberá tratarse de una transmisión de una unidad de negocio, de una explotación económica capaz de producir de manera independiente. En tal sentido, no se estará ante una sustitución empresarial que justifique la continuidad de los trabajadores involucrados si se transfieren bienes individuales que no involucren mano de obra ligada a aquellos, como, por ejemplo, el caso de una maquinaria que no implique la realización de un proceso productivo. En todo caso, el análisis de la aplicabilidad del principio de continuidad frente a una sustitución empresarial deberá realizarse casuísticamente, atendiendo a las circunstancias de la operación concreta.

\subsection{Regulación local del principio de continuidad}

En las líneas que siguen, se comentará brevemente la manera en que ha evolucionado la regulación sobre el principio de continuidad ${ }^{35}$; luego se abordará la situación actual.

30 Martín Valverde, Rodríguez-Sañudo y García Murcia, Derecho del trabajo, 661.

31 Sentencia del Tribunal Supremo Español, Sala Cuarta de lo Social, del 27 de octubre de 1994.

32 Sentencia del Tribunal Supremo Español, Sala Cuarta de lo Social, del 3 de marzo de 1983.

33 Sentencia del Tribunal Supremo Español, Sala Cuarta de lo Social, del 29 de marzo de 1985.

34 Sentencia del Tribunal Supremo Español, Sala Cuarta de lo Social, del 13 de junio de 1985.

35 Para efectos de la evolución normativa del principio de continuidad, se remite al exhaustivo desarrollo que efectúa Morales Corrales, «Sucesión empresarial», en Los Principios del derecho del trabajo, 264-272. 


\subsubsection{Evolución normativa}

\section{Ley 2259}

La Ley 2259 del 29 de setiembre de 1916 determinaba en su artículo 1 que «El dueño de un establecimiento comercial o industrial, que desee traspasarlo y el que se propone adquirirlo, deberán publicar avisos durante quince días en el periódico del lugar, notificando a los acreedores para que concurran al domicilio que se expresará en los avisos, a percibir el importe de sus créditos, o a dejar constancia de su cuantía...». Asimismo, establecía que:

... los traspasos realizados con las publicaciones preceptuadas en el artículo anterior, constituyen responsables al adquiriente solidariamente con el enajenante, de las deudas que consten en los libros del establecimiento; y de las contraídas a favor de las personas que se hayan presentado durante el término fijado en el mismo artículo, siempre que estas deudas sean debidamente comprobadas y que se refieran a operaciones del establecimiento traspasado [...] Si el traspaso se realiza sin hacer las publicaciones fijadas [...] el adquiriente responde solidariamente con el vendedor, de todas las deudas que contraídas antes del traspaso, se refieren a operaciones del establecimiento traspasado (artículos 2 y 3 ).

Al respecto, coincidimos con Morales Corrales ${ }^{36}$ cuando afirma que «aun cuando el Derecho del Trabajo en esa época, tal como lo conocemos hoy en día era absolutamente incipiente y que las relaciones con los empleados se encontraban aún reguladas por el Código de Comercio, debería entenderse que en el supuesto de traspaso de negocios se establecía responsabilidad solidaria entre el adquiriente y el enajenante por el pago de los créditos laborales».

\section{Reglamento de la Ley 4916, artículos 49 y 69}

La Resolución Suprema del 22 de junio de 1928, Reglamento de la Ley 4916 (Ley del Empleado), en su capítulo IV, «De las indemnizaciones», artículo 49, establecía expresamente que «en el caso de venta, fusión de negocios, traspaso o cambio de giro del negocio, conservarán los empleados todos los derechos que la ley acuerda y no podrán ser despedidos sino con el aviso anticipado

36 Morales Corrales, «Sucesión empresarial», en Los principios del derecho del trabajo, 265. 
y con las indemnizaciones y beneficios establecidos en la ley. Si los empleados permanecieran al servicio del nuevo principal, este tomará en cuenta el tiempo de servicios devengados para su oportunidad». Sin embargo, en la Resolución del Tribunal de Trabajo del 24 de setiembre de 1985, se señalaba que debía tenerse en cuenta que el traspaso de negocio no se presume y que debe probarse expresamente, aun cuando exista un negocio similar al que se conducía anteriormente en el mismo local ${ }^{37}$.

En consecuencia, y siguiendo a Morales Corrales ${ }^{38}$, en el supuesto de la sucesión empresarial regulada por el artículo 49 del reglamento de la mencionada ley, se preveía no solo que los trabajadores continuarían conservando todos los derechos que la ley les concede, sino que, en caso de despido, el nuevo empleador tendría que reconocerles el pago de las indemnizaciones (compensación por tiempo de servicios), estableciéndose de manera taxativa que, si los empleados permanecían al servicio del nuevo empleador, este debía tomar en cuenta el tiempo de servicios devengados para su oportunidad.

El capítulo V del Reglamento de la Ley 4916, referido al Régimen del Seguro - beneficio social consagrado por la Ley 4916 y obligatorio a partir de los cuatro años de servicios ininterrumpidos prestados por el empleado-, estableció en su artículo 69, de manera similar a la compensación por tiempo de servicios, que: «En caso de fusión de negocios o de transferencias de negocios de un principal a otro, el nuevo patrón calculará para los efectos de la ley, como servicios ininterrumpidos del empleado los años de servicios prestados al antiguo principal». Así, este dispositivo enfatizaba el reconocimiento por el nuevo empleador del tiempo de servicios acumulado por el trabajador con su anterior empleador.

Respecto de lo anterior, Jorge M. Angulo, citado por Morales Corrales, da cuenta de la Ejecutoria del 15 de enero de 1981 del Tribunal del Trabajo, el cual precisó que «si se prueba que la actual sociedad anónima es continuación del negocio anterior, procede ordenar la entrega de las pólizas de vida con todas las adicionales al día por todo el tiempo de servicios...» ${ }^{39}$.

37 Alfonso de los Heros y Pedro Morales Corrales, Manual de jurisprudencia laboral (Lima: H \& M Ediciones y Servicios, 1997), 336.

38 Morales Corrales, «Sucesión empresarial», en Los principios del derecho del trabajo, 266.

39 Morales Corrales, «Sucesión empresarial», en Los principios del derecho del trabajo, 268. 


\section{Decreto Supremo del 14 de abril de 1944}

El 14 de abril de 1944 entró en vigencia un decreto supremo que amplió y modificó los artículos 49 y 69 del Reglamento de la Ley 4916 antes glosados. La nueva norma estableció que, si con ocasión del traspaso del negocio o modalidades similares, el adquiriente quería liberarse de la responsabilidad del pago de indemnizaciones, así como de los demás derechos y beneficios de los empleados y obreros por el tiempo de servicios anterior al traspaso, el pacto correspondiente debía ser celebrado en el mismo instrumento en que constara la venta, cesión, traspaso, locación o fusión de negocios.

Además, era necesario que antes de la formalización del instrumento se efectuara la liquidación de los derechos y beneficios de los trabajadores, hasta el momento en que se celebraba el contrato o tuviera lugar el acto y que los dependientes interesados hubieran expresado por escrito su conformidad con la liquidación practicada. El importe íntegro de la liquidación aceptada por los dependientes interesados debía consignarse en la antigua Caja de Depósitos y Consignaciones (cuyas funciones cumple hoy en día el Banco de la Nación) el mismo día en que se formalizase el instrumento respectivo y a la orden de la Dirección General del Trabajo. Ante esta se tenía que presentar, asimismo, una solicitud para aprobar la liquidación y la consignación efectuadas dentro del tercer día siguiente al de la formalización del instrumento. Para el efecto la mencionada dirección debía expedir una resolución aprobatoria.

Por otra parte, el citado decreto supremo refería expresamente que, además de los empleados, también los obreros estaban comprendidos como beneficiarios de lo establecido en los artículos 49 y 69 del Reglamento de la Ley 4916 y en los alcances del pacto liberatorio.

\section{Resolución Suprema del 5 de julio de 1944}

Esta norma declaró que el artículo 49 del Reglamento de la Ley 4916 no era aplicable al Estado cuando este asumía la propiedad o administración de servicios que antes habían estado a cargo de entidades privadas — salvo pacto en contrario-, de producirse un traspaso contractual de dichos servicios. 


\section{Ley 10624 y su Reglamento}

La Ley 10624 del 10 de julio de 1946 estableció que las empresas que contaban con un determinado capital estaban obligadas a jubilar con sueldo íntegro a sus empleados que acreditaran cuarenta años de servicios.

Esta norma fue objeto de diversas modificaciones, hasta que posteriormente el Fondo Especial de Jubilación de Empleados Particulares, regulado por el Decreto Ley 17262 del 29 de noviembre de 1968, se hizo cargo de este régimen pensionario para los empleados que ingresaron a laborar antes del 11 de julio de 1962, siempre que acreditaran 25 o más años de servicios al mismo empleador o 20 o más años de servicios en el caso de empleadas.

El Decreto Supremo del 7 de abril de 1947, Reglamento de la Ley 10624, contempló en sus artículos 8 y 10 que el empleado al servicio de una persona individual o de una persona colectiva que no sea sociedad mercantil, al transformarse el negocio, acumulaba el tiempo de servicios prestados antes de dicha transformación para el cómputo de los años necesarios para jubilarse.

Asimismo, de producirse la venta, fusión, traspaso o cambio de giro del negocio, realizado antes o después de la promulgación de la Ley 10624, se consideraban para sus efectos los servicios prestados por el empleado a los anteriores principales, siendo el último de estos el que quedaba obligado al pago de la pensión de jubilación.

\section{Decreto Supremo del 21 de noviembre de 1946}

Mediante Decreto Supremo del 21 de noviembre de 1946, se precisaron los alcances del artículo 1 del Decreto Supremo del 14 de abril de 1944, en el sentido de que el adquiriente de un negocio a título gratuito que no se liberara de la obligación de pagar indemnizaciones estaba obligado a cumplir los requisitos puntualizados en dicho artículo; es decir, a que se practicara con anterioridad a la formalización del instrumento de cesión la liquidación de los derechos y beneficios del personal hasta el momento en que se celebrara el contrato, con la constancia de que los trabajadores hubieran expresado por escrito su conformidad; que se consignara en la Caja de Depósitos y Consignaciones el importe de la liquidación, debiéndose presentar a la Dirección General de Trabajo una solicitud para la aprobación de la liquidación y de la consignación efectuadas. 


\section{Decreto Supremo del 14 de setiembre de 1957}

Mediante este Decreto Supremo se estableció que en el caso de traspaso de negocios se aplicaban las disposiciones de los decretos supremos del 11 de enero de 1942 y del 22 de agosto de 1953. El primero de ellos se refería a la obligatoriedad de los empleadores de solicitar autorización a la Dirección de Trabajo, Asistencia y Previsión Social para que se autorizara la paralización total o parcial de actividades de la empresa, así como el aumento o disminución de la remuneración y de horas de trabajo, o la modificación de la organización y el régimen del trabajo; el segundo desarrolló la norma anterior.

Morales Corrales ${ }^{40}$ afirma que «en el fondo, lo que establecía el Decreto Supremo del 14 de setiembre de 1957 era que, para el caso de traspaso de negocios debía solicitarse autorización previa a la Dirección de Trabajo, con lo cual esta figura, como las otras similares, ya no pudieron ser realizadas de manera privada, es decir sin intervención del Estado».

\section{Decreto Supremo del 27 de setiembre de 1957}

Pocos días después, el 27 de setiembre de 1957, se dictó un nuevo decreto supremo, en el que se estableció que la exigencia de la autorización previa por la Dirección de Trabajo no era necesaria cuando el adquiriente asumía un negocio y mantenía el $60 \%$ o un porcentaje mayor de trabajadores que estuvieron al servicio del cedente. En caso contrario, o si el adquiriente no asumía tal compromiso, requería de la autorización correspondiente.

\subsubsection{Situación actual}

\section{Ley 26513}

El 29 de julio de 1995 entró en vigencia la Ley 26513, con lo cual quedó derogada la Ley 4916 y, por tanto, sus normas modificatorias y complementarias antes mencionadas. A partir de entonces, no existe regulación sobre las consecuencias laborales en los casos de venta, fusión, traspaso, cambio de giro del negocio y figuras similares.

40 Morales Corrales, «Sucesión empresarial», en Los principios del derecho del trabajo, 272. 
Sin embargo, consideramos que el principio de continuidad es válido cuando se producen estas figuras, puesto que, tratándose de un principio del derecho, no requiere su plasmación normativa para ser perfectamente aplicable ${ }^{41}$.

\section{Decreto Supremo 010-2003-TR, Texto Único Ordenado de la Ley de Relaciones Colectivas de Trabajo}

El artículo 44, literal e) señala que una de las características del convenio colectivo de trabajo consiste en la continuación de su vigencia hasta la expiración de su plazo, en caso de «fusión, traspaso, venta, cambio de giro del negocio y otras situaciones similares». Esta disposición relativa a la convención colectiva de trabajo es la única vigente que regula el efecto de la sustitución de empleador en las relaciones laborales.

\subsection{Impacto del principio de continuidad laboral en la reorganización societaria}

Como se explicó en los párrafos precedentes, la aplicación del principio de continuidad tiene como efecto que los trabajadores involucrados en una reorganización societaria no vean afectado su vínculo laboral, en cuanto a su tiempo de servicios ni en cuanto a sus condiciones de trabajo. Sin embargo, el hecho del traspaso y la consiguiente asunción de trabajadores trae una serie de consecuencias prácticas, algunas de las cuales detallaremos a continuación.

\subsubsection{Mantenimiento de tiempo de servicios y condiciones de trabajo de personal asumido}

Esta consecuencia, más teórica que práctica - y directamente surgida de la aplicación del mencionado principio-, significa que los trabajadores involucrados en la reorganización societaria provenientes de la empresa que es absorbida, incorporada, escindente o que segrega su patrimonio mantendrán su fecha de ingreso original y, por ende, su tiempo de servicios, para efectos

41 Isabel Herrera Gonzales-Pratto, «Transmisión de empresa y principio de continuidad», Asesoría Laboral 67 (1996): 23-25. 
del cálculo de sus derechos y beneficios de carácter laboral. Esto tendrá efectos en el cálculo de una eventual indemnización por despido arbitrario ${ }^{42}$ y en el récord para el pago de la prima del seguro de vida ley ${ }^{43}$.

En cuanto a las vacaciones, gratificaciones y compensación por tiempo de servicios que se devengaron durante la relación laboral por el periodo anterior a la sustitución del empleador, se entiende que fueron canceladas o depositadas en su oportunidad. De lo contrario, deberán liquidarse respetando la fecha original de ingreso del trabajador. Con respecto a los aportes previsionales, el trabajador involucrado en la reorganización societaria continuará aportando a su fondo previsional sin solución de continuidad, ya sea en una cuenta individual de capitalización o en un fondo común, debiendo comunicar la transferencia de personal a la Sunat o a la administradora privada de fondos de pensiones, según corresponda.

\subsubsection{Responsabilidad de la nueva empresa respecto de las deudas laborales de la anterior}

Al transferirse una empresa, además del pasivo comercial propio del giro o actividad que desarrolla, suele existir un pasivo que puede no estar cuantificado a nivel contable, referido a diferencias en el monto de remuneraciones y beneficios laborales que, en su momento, pueden originar reclamos. Coincidimos con Plá ${ }^{44}$, quien afirma al respecto que: «si continúan los mismos contratos de trabajo con un simple cambio de empleador, la misma empresa —aun cuando esté total o parcialmente a cargo de otro titular - sigue como deudora de todas las obligaciones laborales pendientes, aunque se hayan originado con anterioridad».

42 Recuérdese que el artículo 34 del Texto Único Ordenado del Decreto Legislativo 728, Ley de Productividad y Competitividad Laboral, aprobado por Decreto Supremo 003-97-TR, establece que: «Si el despido es arbitrario por no haberse expresado causa o no poderse demostrar esta en juicio, el trabajador tiene derecho al pago de la indemnización establecida en el Artículo 38, como única reparación por el daño sufrido...». Dicha indemnización equivale a una remuneración y media mensual por cada año completo de servicios con un máximo de doce remuneraciones mensuales.

43 Como lo establece el Decreto Legislativo 688, Ley de Consolidación de Beneficios Sociales, el trabajador tiene derecho al seguro de vida a cargo de su empleador a los cuatro años de servicios, siendo dicho tiempo de servicios acumulativo; es decir, en caso de que el trabajador haya prestado servicios en beneficio en diferentes periodos, estos se sumarán a efectos del cálculo de los cuatro años.

44 Plá Rodríguez, Los principios del derecho del trabajo, 304. 
No comparto aquellas posiciones que afirman que existiría responsabilidad solidaria entre la empresa cedente y la adquirente del negocio, por cuanto no existe norma expresa que así lo establezca, salvo que haya un acuerdo en dicho sentido. Debe recordarse que en aplicación del artículo 1183 del Código Civil, «la solidaridad no se presume. Solo la ley o el título de la obligación la establecen en forma expresa». En relación con esto, el jurista Felipe Osterling ${ }^{45}$ señala que: «A través del artículo 1183 del Código Civil Peruano se establece que la solidaridad no se presume; y que solamente en virtud de la ley o del título de la obligación se le puede establecer en forma expresa. La razón de este precepto radica en la grave onerosidad que representa para uno o varios deudores obligarse respecto de uno o varios acreedores de manera solidaria».

La no presunción de solidaridad ha sido recogida en las siguientes resoluciones judiciales:

a) Resolución del Tribunal de Trabajo del 9 de octubre de 1984, expediente 3134-83. Establece que la solidaridad, en cuanto al cumplimiento de obligaciones, no se presume ni se puede declarar en forma fehaciente, porque solo hay lugar para ello cuando en forma expresa lo determinan la ley o la obligación.

b) Resolución de la Sala Laboral de Lima del 18 de junio de 1998, expediente 974-98-BS. Señala que la presunción de solidaridad no se encuentra permitida, de acuerdo con lo normado en el artículo 1183 del Código Civil.

c) Resolución de la Sala Laboral de Lima del 1 de diciembre de 1998. También sostiene que, según el artículo 1183 del Código Civil, la solidaridad no puede presumirse.

d) Resolución de la Sala Laboral de Lima del 1 de junio de 1998. Señala, igualmente, que la solidaridad no puede presumirse, de acuerdo con el artículo 1183 del Código Civil.

En tal sentido, será a la empresa adquirente a la que le corresponda el reconocimiento y el pago de los derechos que puedan haberse devengado por la prestación de los servicios del personal en la empresa o empresas cedentes.

Para minimizar sus riesgos, usualmente el adquirente consigna cláusulas de protección en el sentido de que el cedente le reembolsará los pagos por derechos y beneficios sociales que deba efectuar y que correspondan al tiempo de servicios prestados al cedente hasta la fecha de la transmisión. La empresa

45 Felipe Osterling Parodi y Mario Castillo Freyre. Tratado de las obligaciones, tomo 3 (Lima: Fondo Editorial de la Pontificia Universidad Católica del Perú, 2001), 209. 
que se reorganiza y traspasa a su personal debería efectuar una auditoría de todo lo que se pueda adeudar a los trabajadores que van a ser transferidos y abonar a quien corresponda, por ejemplo, vacaciones no disfrutadas, gratificaciones, CTS, horas extras, participación en las utilidades ${ }^{46}$, asignación familiar, aportaciones sociales, etc., de tal modo que a la fecha de traspaso todo se encuentre en orden.

\subsubsection{Duplicidad de personal}

Una situación que se origina a raíz de la asunción de trabajadores producto de una reorganización societaria es la duplicidad del personal que proviene, ya sea de la empresa absorbida, incorporada, escindente o de la que transfiere un bloque patrimonial.

El profesor Plá ${ }^{47}$, refiriéndose a la duplicidad del personal de dirección, señala inclusive que «el problema puede complicarse si los valores, las aptitudes, las condiciones individuales de los titulares de estos cargos, no coinciden con la importancia o el volumen de las empresas de donde provienen, es decir, si el gerente de la empresa absorbida es mucho más capaz que el de la absorbente o tiene mayor experiencia o posee notoriamente mejores calificaciones profesionales...».

Creemos que este supuesto puede solucionarse en el ordenamiento peruano mediante la celebración de convenios de modificación de condiciones de trabajo, a efectos de reorganizar al personal asumido. En todo caso, esta duplicidad puede ser prevista antes de la entrada en vigencia de la reorganización societaria a fin de tomar las medidas adecuadas para la reducción del personal excedente, de no ser posible su reubicación, la cual pasará por acuerdos de cese o renuncias, entre otros.

\footnotetext{
46 En cuanto a la participación en las utilidades, conviene señalar que, de conformidad con el artículo 8 del Decreto Legislativo 892, concordante con el artículo 17 de su Reglamento, el Decreto Supremo 009-98-TR, en caso de fusión se realizará una separación (corte) a la fecha del otorgamiento de la escritura pública de fusión para la determinación del monto a pagar a los trabajadores de cada empresa.

47 Plá Rodríguez, Los principios del derecho del trabajo, 308.
} 


\subsubsection{Armonización de jerarquías funcionales}

Un caso similar al anterior se refiere a la jerarquía de las funciones desempeñadas por los trabajadores procedentes de la empresa que se reorganiza. Se presenta el problema de ensamblamiento en los distintos niveles, con lo cual surge el cuestionamiento válido que hace Plá en el sentido de que, si por esta vía no se pierden o desperdician cuadros muy importantes o se esterilizan o inutilizan condiciones, conocimientos y experiencias muy útiles y valiosas ${ }^{48}$. Adicionalmente, Plá afirma que, «las dificultades de integración y armonización repercuten desfavorable y negativamente en el rendimiento del conjunto» ${ }^{49}$.

Creemos que son aplicables las medidas referidas en el punto 3.4.3. precedente, sobre la duplicidad del personal.

\subsubsection{Desigualdad de nivel remunerativo}

En la práctica ocurre el caso de que los trabajadores provenientes de la empresa o empresas que se reorganizan - y que, por ende, son absorbidas o se incorporan a una nueva, son objeto de una escisión o segregan un patrimonio- percibían una remuneración distinta de la que perciben los trabajadores de la empresa que los asume.

No es conveniente admitir sectores privilegiados dentro de un conjunto ni diferencias que no se justifiquen, ya que el mantenimiento de una situación desigual no es visto con simpatía por el personal de la empresa ${ }^{50}$. Para equiparar la situación, se podrán celebrar acuerdos por escrito con el personal a fin de reestructurar el sistema remunerativo, para lo cual se requiere una justificación objetiva que lo permita.

48 Plá Rodríguez, Los principios del derecho del trabajo, 309.

49 Plá Rodríguez, Los principios del derecho del trabajo, 309.

50 Es ilustrativo señalar que, en opinión de la Corte Suprema, la cual compartimos, no constituye acto discriminatorio el hecho de otorgar remuneración diferenciada a los trabajadores que realizan diferentes labores, ya que no existe violación al principio de igualdad entre quienes se hallan en situaciones diferentes, la cual obedece a causas objetivas (Casación 100-2004 Lima, publicada en el Diario oficial El Peruano, 31 de octubre de 2005). 


\subsection{Principio de continuidad y fusión}

Luego del marco teórico expuesto, corresponde reflexionar sobre la forma en la que opera el principio de continuidad ante una fusión, escisión o reorganización simple. La principal cuestión por determinar es si se necesita el consentimiento del personal involucrado en la reorganización o basta la voluntad del empleador para que ocurra la sustitución de este.

Con respecto a la reorganización empresarial, es evidente que la decisión de llevarla a cabo no requiere el concurso de la parte laboral, en tanto se fundamenta en la libertad de empresa, reconocida expresamente en nuestra Constitución ${ }^{51}$. Rubio Correa afirma con acierto que «la libertad de empresa consiste en la posibilidad de manejar libremente la actividad empresarial, dentro de los marcos de la Constitución y la ley» ${ }^{52}$.

El Tribunal Constitucional peruano, al pronunciarse sobre la libertad de empresa en la sentencia recaída en el expediente 3330-2004-AA/TC, ha señalado en su fundamento 13 que el contenido de aquella comprende cuatro libertades: la libertad de creación de empresa y de acceso al mercado (libertad para emprender actividades económicas), la libertad de organización (la libre elección del objeto, nombre, domicilio, tipo de empresa o de sociedad mercantil, contratación de personal entre otras), la libertad de competencia y la libertad para cesar las actividades (disponer el cierre o cesación de las actividades cuando lo considere más oportuno).

Entonces, la decisión de ejecutar alguna de las formas de reorganización empresarial será tomada por el empleador de manera unilateral. A nuestro entender, sin embargo - y salvo que se trate de una fusión-, consideramos que el trabajador debe manifestar su consentimiento para poder ser trasladado a la empresa que ocupe el lugar del empleador, en razón del cambio de su titularidad. En otras palabras, para que el trabajador se traslade «siguiendo» a la unidad económica que es traspasada con ocasión de la reorganización, se requerirá su consentimiento. Ello en aplicación del derecho a la libertad de trabajo, que permite al trabajador decidir en favor de quién va a trabajar ${ }^{53}$.

51 Artículo 59: «El Estado estimula la creación de riqueza y garantiza la libertad de trabajo y libertad de empresa, comercio e industria. El ejercicio de estas libertades no debe ser lesivo a la moral, ni a la salud ni a la seguridad públicas».

52 Marcial Rubio Correa, Estudio de la Constitución Política del Perú (Lima: Fondo Editorial de la Pontificia Universidad Católica del Perú, 1999), tomo 3, 227.

53 Al respecto véase: Javier Neves Mujica, «Libertad de trabajo, derecho al trabajo y derecho de estabilidad en el trabajo», Derecho y Sociedad 17 (2001): 24. 
Lo anterior en razón de que el empleador puede de manera unilateral decidir sobre el futuro de su negocio, pero en modo alguno modificar de forma esencial las relaciones laborales de su personal, al extremo tal de traspasar a los trabajadores a una empresa distinta que ocupará la posición de empleador en la relación laboral. Debe recordarse que al empleador titular de la organización le asiste el derecho de modificar las condiciones de trabajo de su personal, pero, observamos, dentro de ciertos límites ${ }^{54}$.

La legislación peruana recoge esta facultad en el artículo 9 del Decreto Supremo 003-97-TR, al señalar que «el empleador está facultado para introducir cambios o modificar turnos, días u horas de trabajo, así como la forma y modalidad de la prestación de las labores, dentro de criterios de razonabilidad y teniendo en cuenta las necesidades del centro de trabajo». ¿Esta facultad alcanza a la sustitución patronal? Opinamos que no. La sola voluntad del empleador no determina el traspaso de trabajadores cuando ocurre una escisión o reorganización simple.

¿Qué ocurre si el trabajador no está de acuerdo con ser transferido conjuntamente con la unidad de negocio? Pues su relación laboral se mantendrá con el empleador que cede su bloque patrimonial, o que se escinde. Desde luego, esto podría resultar contradictorio con el hecho de que probablemente no exista labor efectiva para esa persona al haberse traspasado su centro de trabajo; en esta situación, lo natural es reducir a ese personal excedente antes de la entrada en vigencia de la reorganización empresarial. Sostener lo contrario supondría avalar, por ejemplo, que una empresa podría escindir un área con la finalidad de desarticular al sindicato o cesar al personal sin tener que indemnizarlo. Ello nos parece poco coherente con el principio de continuidad, pues, así como surge el derecho de continuar cuando el trabajador presta su anuencia para ser transferido, también subsiste el mencionado derecho si el trabajador se niega.

En la fusión ocurre algo distinto, toda vez que la transferencia de las sociedades absorbidas a la absorbente o de las fusionantes a la nueva sociedad ocurre a título universal. Esto supone que los contratos de trabajo también son transferidos sin que se requiera el consentimiento del personal involucrado.

54 Véase Óscar Ermida Uriarte, Modificación de condiciones de trabajo por el empleador (Buenos Aires: Editorial Hammurabi, 1989). 
Debe en este punto referirse a la cesión de posición contractual, contemplada en el artículo 1435 del Código Civil ${ }^{55}$, mediante la cual el trabajador podrá ser cedido de una empresa a otra, previo consenso de voluntades de las partes intervinientes. Este supuesto de sustitución del empleador se materializa con la celebración de un acuerdo tripartito entre el cedente (empresa 1), el cesionario (empresa 2) y el cedido (trabajador), y tiene como efecto que los términos y condiciones de la relación jurídico-laboral entre la empresa 1 y el cedido se mantienen inalterados en la nueva relación que se entable con la empresa 2. En otras palabras, al trabajador se le mantendrá la antigüedad laboral, las remuneraciones y demás condiciones de trabajo, pero no por la aplicación del principio de continuidad laboral, sino por expreso mandato del Código Civil, que, como sabemos, se aplica supletoriamente a las relaciones de trabajo en tanto guarde coherencia con su naturaleza jurídica. Dicha cesión de posición contractual no supone la ocurrencia de una reorganización empresarial, pudiendo presentarse, por ejemplo, ante la circulación de trabajadores en un grupo empresarial.

Cuando suceda la reorganización, el acuerdo del trabajador para su traspaso también podría plasmarse en un documento tripartito similar al que se suscribe ante una cesión de posición contractual, pero su fundamento no será el artículo 1435 del Código Civil, sino el carácter bilateral del contrato de trabajo y la limitación al ius variandi contenida en el artículo 9 citado anteriormente. Una medida alternativa - y válida también a nuestro entenderconsiste en que el trabajador labore normalmente para la nueva empresa que ocupa el lugar de empleador, entendiéndose tácitamente que ha manifestado su conformidad con el cambio. Recuérdese que la manifestación de voluntad puede ser expresa o tácita, aunque en materia laboral se prefiere siempre la expresa, pues el trabajador puede acatar la orden y luego reclamarla.

Conocemos que la Corte Suprema ha opinado en sentido distinto en la Casación 1162-2013, pronunciamiento que no compartimos, en tanto que en el numeral 2.5 del considerando segundo señala que, en la transmisión de empresas, «no es necesario el consentimiento del trabajador de la empresa origi-

55 Artículo 1435: «En los contratos con prestaciones no ejecutadas total o parcialmente, cualquiera de las partes puede ceder a un tercero su posición contractual. Se requiere que la otra parte preste su conformidad antes, simultáneamente o después del acuerdo de cesión. Si la conformidad del cedido hubiera sido prestada previamente al acuerdo entre cedente y cesionario, el contrato solo tendrá efectos desde que dicho acuerdo haya sido comunicado al cedido por escrito de fecha cierta». 
naria, toda vez que el traspaso de trabajadores en dicho escenario resulta imperativo para que la unidad económica y social (empresa) continúe desarrollando su actividad productiva...». Como se ha mencionado anteriormente, la transferencia automática de trabajadores en un escenario de reorganización empresarial es improcedente en la medida en que se infringiría su derecho a la libertad de trabajo. El poder de dirección no permite que el empleador tome una decisión estructural de tal magnitud sin el consentimiento del trabajador.

\section{Conclusiones}

La reorganización societaria trae una serie de consecuencias para las relaciones laborales del personal involucrado en aquella, muchas de las cuales no son advertidas por las empresas involucradas cuando no cuentan con una asesoría especializada en materia laboral.

Se debe tener en cuenta que, en aplicación del principio de continuidad de la relación laboral — cuya plasmación en el ordenamiento jurídico peruano no es indispensable para su operatividad-, las relaciones de trabajo no se ven afectadas por la sustitución del empleador, pues, salvo casos excepcionales, la prestación de este no es intuito personae (personalísima).

No debe de perderse de vista, sin embargo, que el principio de continuidad no puede imponerse a la voluntad de las partes, en particular del trabajador, y con ello pretender transferirlo de empresa sin contar con su consentimiento, sea expreso o tácito. Sostener lo contrario abriría la puerta a que algunas decisiones empresariales de transformación societaria se sustenten no en una natural lógica de eficiencia, sino en el interés de afectar los derechos laborales del personal, situación contraria a lo que propugna el derecho del trabajo.

Las normas societarias vigentes no abordan el tema laboral, y, salvo la regulación de la fusión que se refiere a una "adquisición a título universal», no se tiene una mínima referencia a lo que sucede con los contratos de trabajo ante la ocurrencia de una escisión o una reorganización simple. Entonces, no resulta razonable señalar que, si el centro de trabajo cambia de titular, el trabajador debe seguirlo como si se tratase de un elemento accesorio al principal. Ello dependerá de la voluntad del trabajador.

Peor aún, podría emplearse como justificación de esta «transferencia automática de trabajadores» el hecho de que se le reconoce al trabajador su 
antigüedad y condiciones de trabajo en la nueva empresa, en aplicación del principio de continuidad. Si la base de los principios del derecho del trabajo es la tutela del trabajador, mal se puede invocar el principio de continuidad para justificar el desconocimiento de su derecho a la continuidad en el empleo anterior. 


\section{ReFERENCIAS}

Alonso Olea, Manuel y María Emilia Casas Baamonde. Derecho del trabajo. Madrid: Civitas, 2001.

De los Heros Pérez Albela, Alfonso. «Los contratos de trabajo de duración determinada: ¿regla o excepción?». En Los principios del derecho del trabajo en el derecho peruano. Libro homenaje al profesor Américo Plá Rodríguez. Lima: Grijley, 2004.

De los Heros, Alfonso y Pedro Morales Corrales. Manual de jurisprudencia laboral. Lima: H \& M Ediciones y Servicios, 1997.

Elías Laroza, Enrique. Derecho societario peruano. Trujillo: Normas Legales, 2000.

Ermida Uriarte, Óscar. Modificación de condiciones de trabajo por el empleador Buenos Aires: Editorial Hammurabi, 1989.

Herrera Gonzales-Pratto, Isabel. «Transmisión de empresa y principio de continuidad». Asesoría Laboral 67 (1996): 23-25.

Manual societario, tomo 2. Lima: Editorial Economía y Finanzas, s. f.

Martín Valverde, Antonio, Fermín Rodríguez-Sañudo Gutiérrez y Joaquín García Murcia. Derecho del Trabajo. 5. ${ }^{\text {a }}$ ed. Madrid: Tecnos, 1996.

Morales Corrales, Pedro. «Sucesión empresarial». En Los Principios del derecho del trabajo en el derecho peruano. Libro homenaje al profesor Américo Plá Rodríguez. Lima: Grijley, 2004.

Neves Mujica, Javier. «Libertad de trabajo, derecho al trabajo y derecho de estabilidad en el trabajo». Derecho y Sociedad 17 (2001): 24-26. http:// revistas.pucp.edu.pe/index.php/derechoysociedad/article/view/16787

Osterling Parodi, Felipe y Mario Castillo Freyre. Tratado de las obligaciones, tomo 3, Biblioteca para Leer el Código Civil. Lima: Fondo Editorial de la Pontificia Universidad Católica del Perú, 2001. 
Plá Rodríguez, Américo. Los principios del derecho del trabajo. 3. a ed. Buenos Aires: Depalma, 1998.

Rubio Correa, Marcial. Estudio de la Constitución Política del Perú, tomo 3. Lima: Fondo Editorial de la Pontificia Universidad Católica del Perú, 1999.

\section{Sobre el autor}

Abogado y magíster en Derecho del Trabajo y la Seguridad Social por la Pontificia Universidad Católica del Perú. Profesor de la Universidad ESAN, en la Carrera de Derecho Corporativo, la Maestría de Finanzas y Derecho Corporativo y cursos de posgrado; también de la Pontificia Universidad Católica del Perú, en la Maestría de Derecho del Trabajo y la Seguridad Social; y de la Universidad San Martín de Porres, en la Maestría de Derecho del Trabajo. Miembro de la Sociedad Peruana de Derecho del Trabajo y la Seguridad Social. 